\title{
EGFR NP_005219.2:p.E709fs*1
}

National Cancer Institute

\section{Source}

National Cancer Institute. EGFR NP 005219.2:p.E709fS*1. NCI Thesaurus. Code C98530.

A change in the amino acid composition of the epidermal growth factor receptor protein where a frame shift mutation results in the placement of a stop codon just after the glutamic acid residue at position 709. 